EarthArXiv coversheet for:

\title{
Building back bigger in hurricane strike zones
}

Eli D Lazarus ${ }^{1 \star}$, Patrick W Limber ${ }^{2,3}$, Evan B Goldstein ${ }^{4,5}$, Rosie Dodd ${ }^{6}$ \& Scott B Armstrong ${ }^{1}$

${ }^{1}$ Environmental Dynamics Lab, School of Geography \& Environmental Science, University of Southampton, Southampton, UK

2 Department of Marine Science, Coastal Carolina University, Conway, South Carolina, USA

${ }^{3}$ Pacific Coastal and Marine Science Center, United States Geological Survey, Santa Cruz, California, USA

${ }^{4}$ Department of Geological Sciences, University of North Carolina, Chapel Hill, North Carolina, USA

${ }^{5}$ Now at Department of Geography, Environment, and Sustainability, University of North Carolina at Greensboro, Greensboro, North Carolina, USA

${ }^{6}$ School of Earth \& Ocean Sciences, Cardiff University, Cardiff, UK

${ }^{*}$ Correspondence to: E.D.Lazarus@soton.ac.uk

This article is a postprint from Nature Sustainability. The journal permits the distribution of Author's Accepted Manuscript 6 months after publication. Any citation of this article should us the Nature Sustainability citation:

Lazarus, ED, PW Limber, EB Goldstein, R Dodd, SB Armstrong, (2018) Building back bigger in hurricane strike zones, Nature Sustainability, 1, 759-762, http://doi.org/10.1038/ 
1 Building back bigger in hurricane strike zones

2 Eli D Lazarus ${ }^{1}$, Patrick W Limber ${ }^{2,3}$, Evan B Goldstein ${ }^{4}$, Rosie Dodd ${ }^{5} \&$ Scott B

3 Armstrong ${ }^{1}$

4

$5 \quad{ }^{1}$ Environmental Dynamics Lab, School of Geography \& Environmental Science,

6 University of Southampton, Southampton, UK

$7 \quad{ }^{2}$ Department of Marine Science, Coastal Carolina University, Conway, South Carolina,

8 USA

$9{ }^{3}$ Pacific Coastal and Marine Science Center, United States Geological Survey, Santa Cruz,

10 California, USA

$11{ }^{4}$ Department of Geological Sciences, University of North Carolina, Chapel Hill, North

12 Carolina, USA

$13{ }^{5}$ School of Earth \& Ocean Sciences, Cardiff University, Cardiff, UK

*Correspondence to: E.D.Lazarus@soton.ac.uk

ORCIDs:

ED Lazarus 0000-0003-2404-9661

PW Limber 0000-0002-8207-3750

EB Goldstein 0000-0001-9358-1016

SB Armstrong 0000-0001-9567-5964

Despite decades of regulatory efforts in the US to decrease vulnerability in developed coastal zones, exposure of residential assets to hurricane damage is increasing - even in places where hurricanes have struck before. Comparing planview footprints of individual residential buildings prior to and long after major hurricane strikes, we find a systematic pattern of "building back bigger" among renovated and new properties.

Storm impacts on developed coastlines are expected to increase with climate change ${ }^{1}$. In coastal counties around the United States, policies intended to mitigate coastal risk are competing with population growth and development pressures ${ }^{1-5}$ that render places more vulnerable and less resilient to major storm events.

Research into the repercussions of hurricane impacts has examined regional- and localscale socioeconomics and demographics ${ }^{6-8}$, housing stock and types ${ }^{8,9}$, planning and design requirements (and variances from them) ${ }^{10-13}$, tax and insurance policy ${ }^{3}$, and real-estate market recovery ${ }^{14}$. But one indicator of increasing vulnerability in hurricane zones is especially enigmatic: residential footprints are growing even in places with legacies of past impacts, including a systematic pattern of "building back bigger" among renovated and new 39 properties.

40 Here, we investigate broad development trends in hurricane alleys. We measure changes over 5-14 years in residential building footprints at five locations on the US Atlantic and

42 Gulf Coasts that have been struck by one or more hurricanes since 2003 (Fig. 1). Each 43 location occupies a developed coastal barrier in a different state, is characterised primarily 
by single-family residential buildings, and is demarcated in FEMA flood-risk maps a Special

45 Flood Hazard Area. Collectively, the locations have weathered six different hurricane systems between 2003 and 2012, and sustained damage from multiple types of impacts (e.g., wind, storm surge, waves). Each location has also had multiple years (5 or more) over which residential recovery could occur. Using satellite imagery captured before the last major hurricane event (or events) at each locale and again in 2017 (the most recent year of coverage available at all five locations, and collected prior to the 2017 hurricane season), we digitised the plan-view footprints of individual residential buildings in the pre-storm and 2017 imagery and compared their respective areas.

The resulting statistical distributions of footprint size yield the same pattern at all five locations: since the last major hurricane strike, larger residential buildings have tended to replace smaller ones (Fig. 2a-e). Among buildings whose footprints change (Fig. 2f-j), mean footprint size increases between 19\% (Hatteras) to 49\% (Santa Rosa Island). Mean footprints of new buildings (absent from the pre-storm image but present in 2017) exceed overall pre-storm mean footprints by 14\% (Mantoloking) to 55\% (Santa Rosa Island). Although total footprint area decreases at Mantoloking (-4\%), Dauphin Island (-4\%), and Bolivar (-14\%), the mean size of building footprints overall (insets, Fig. $2 \mathrm{f}-\mathrm{j}$ ) increases at all five locations by 10\% (Mantoloking) to 35\% (Bolivar).

Hypothetically, total footprint area could decrease and mean footprint size increase with preferential destruction or removal of small buildings, without otherwise altering the footprints of existing buildings. We test for this effect by comparing the mean pre-storm footprint of "surviving" buildings - those present in both images - with the mean prestorm footprint overall. The only significant difference we find is at Bolivar (Supplementary Table 2), where smaller houses were disproportionately affected. However, the preferential loss of smaller footprints only accounts for a $9 \%$ increase in mean footprint size, which suggests the remaining 26\% increase that we calculate from 2017 imagery derives from renovated and new buildings. Pre-storm and 2017 distributions of altered footprints (Fig. 2f-j), and of footprints overall (insets), are statistically distinct at all five locations (Supplementary Table 2). Distributions of new footprints are statistically distinct from overall pre-storm distributions everywhere but at Mantoloking, where only nine new houses appear between 2010-2017.

By spanning the longest period possible since the last major hurricane event at a given location, our analysis accommodates both rapid and slow paces of residential recovery. Within those extended timeframes, buildings might be renovated, relocated, or removed for reasons unrelated to a specific hurricane. Our method of comparing building footprints does not reveal information about the cause or extent of storm damages, or about building characteristics such as age, ground-floor elevation, or structural enhancements. However, post-hurricane assessments have demonstrated wide variation in relationships between building characteristics and hurricane damage - even among individual properties at the same location subjected to the same hurricane ${ }^{8,9}$. The fundamental relationship from our analysis is that residential footprints collectively exhibit a systemic pattern of growth in hurricane zones. our analysis), the mean size of new single-family houses increased 14-16\% (Supplementary 
(Supplementary Fig. 1; Supplementary Table 3; Supplementary Methods), they also manifest despite policy measures intended to prevent them. As of 2007, an estimated $16 \%$ of coastal barrier land designated under the Coastal Barrier Resources Act (1982) and Coastal Barrier Reauthorization Act (2000) "experienced development in spite of the federal funding restrictions, encouraged by strong real estate market pressures, the availability of private insurance, and state and local land-use policies that promote floodplain development" ${ }^{2}$. Parcel-scale studies of policy effects in high-risk zones indicate that even places with progressive land-use plans can have idiosyncratic development patterns, typically stemming from local variances that circumvent newer planning rules ${ }^{11}$. Practices of assessment, appraisal, compliance, and enforcement hinge on local and individual discretion and interpretation ${ }^{10-12}$. The development pattern we show across the locations in Fig. 1 surely arose from a number of mechanisms ${ }^{3,5,7-14}$. However, the aggregate effect of those mechanisms - including the tendency to "build back bigger" in hurricane corridors and demarcated coastal flood-risk zones - appears insensitive to their particulars.

By demonstrating an emergent pattern of increased exposure in high-risk coastal development, we intend for our analysis to complement local case studies of land-use policy effects and hazard-mitigation strategies. Related "build-destroy-rebuild" patterns $s^{10,15,16}$ appear in a variety of other hazard settings ${ }^{17,18}$, with critical implications for future management and policy actions ${ }^{2,19}$. Comparative research across different hazard types (e.g., earthquakes, wildfires, tornadoes) $)^{17-19}$ and longitudinal studies quantifying changes to built environments ${ }^{7}$ in vulnerable areas (not limited to the US ${ }^{20}$ ) will help the wider sustainability-science research community to identify, understand, address the economic and policy forces that shape decision-making and risk evolution in places where climate-related hazards are intensifying.

\section{References}

1. Moser, S. C. et al. in Climate Change Impacts in the United States: The Third National Climate Assessment (eds Melillo, J. M., Richmond, T. C. \& Yohe, G. W.) 579-618 (US Global Change Res. Program, 2014).

2. US National Research Council Reducing Coastal Risks on the East and Gulf Coasts (NRC, 2014).

3. Bagstad, K. J., Stapleton, K. \& D'Agostino, J. R. Ecol Econ 63, 285-298 (2007).

4. McNamara, D. E., Gopalakrishnan, S., Smith, M. D. \& Murray, A. B. PLoS One 10, e0121278 (2015).

5. Armstrong, S. B. et al. Earth's Future 4, 626-635 (2016).

6. Dash, N., Morrow, B. H., Mainster, J., \& Cunningham, L. Nat Hazards Rev 8, 13-21 (2007).

7. Peacock, W. G., Van Zandt, S., Zhang, Y. \& Highfield, W. E. I Am Plann Assoc 80, 356-371 (2014).

8. Highfield, W. E., Peacock, W. G. \& Van Zandt, S. J Plan Educ Res 34, 287-300 (2014).

9. van Verseveld, H. C. W., van Dongeren, A. R., Plant, N. G., Jäger, W. S. \& den Heijer, C. Coast Eng 103, 1-14 (2015).

10. Platt, R. H., Salvesen, D. \& Baldwin II, G. H. Coast Manage 30, 249-269 (2002).

11. Deyle, R. E., Chapin, T. S. \& Baker, E. J. J Am Plann Assoc 74, 349-370 (2008).

12. Dyckman, C. S. \& Wood, I. L. Coast Manage 41, 501-536 (2013). 
13. Dehring, C. A. \& Halek, M. Land Econ 89, 597-613 (2013).

134 14. Hallstrom, D. G. \& Smith, V. K. J Environ Econ Manag 50, 541-561 (2005).

135 15. Nordstrom, K. F. \& Jackson, N. L. J Coast Conserv 1, 51-62 (1995).

136 16. Kim, K., \& Olshansky, R. B. J Am Plann Assoc 80, 289-292 (2014).

137 17. Comerio, M. C. J Conting Crisis Man 5, 166-178 (1997).

138 18. Alexandre, P. M. et al. Int J Wildland Fire 24, 138-149 (2015).

139 19. Mileti, D. Disasters By Design (Joseph Henry Press, Washington, DC, 1999).

140 20. Filatova, T. Environ Sci Policy 37, 227-242 (2014).

141 21. Lazarus, E. D., Limber, P. W. \& Goldstein, E. B. Figshare

142 doi:10.6084/m9.figshare.7105835 (2018).

\section{Acknowledgements}

145 This work was supported in part by the Cardiff Undergraduate Research Opportunities

146 Programme (to EDL \& RD), and by the UK NERC BLUEcoast project (to EDL;

147 NE/N015665/2). The authors thank RC Ballinger, P Barnard, and the editors and 148 reviewers.

149

150 Author contributions

151 PWL conceived of the idea; all authors contributed to data collection; EDL, PWL, EBG, 152 and RD conducted the analysis; EDL, EBG, and PWL wrote the manuscript, with 153 contributions from RD and SBA. 


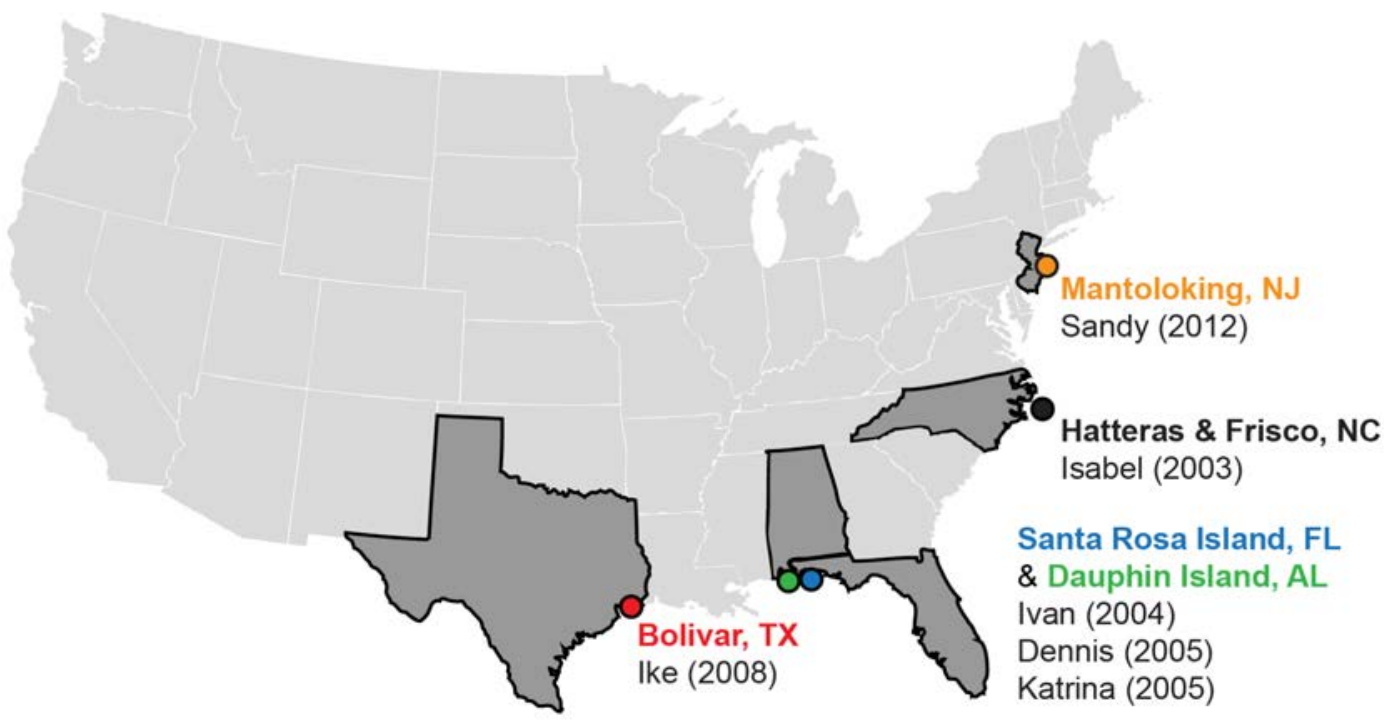

156 Figure 1 | Study locations in hurricane strike zones around the US Atlantic and Gulf 157 Coasts.

158 

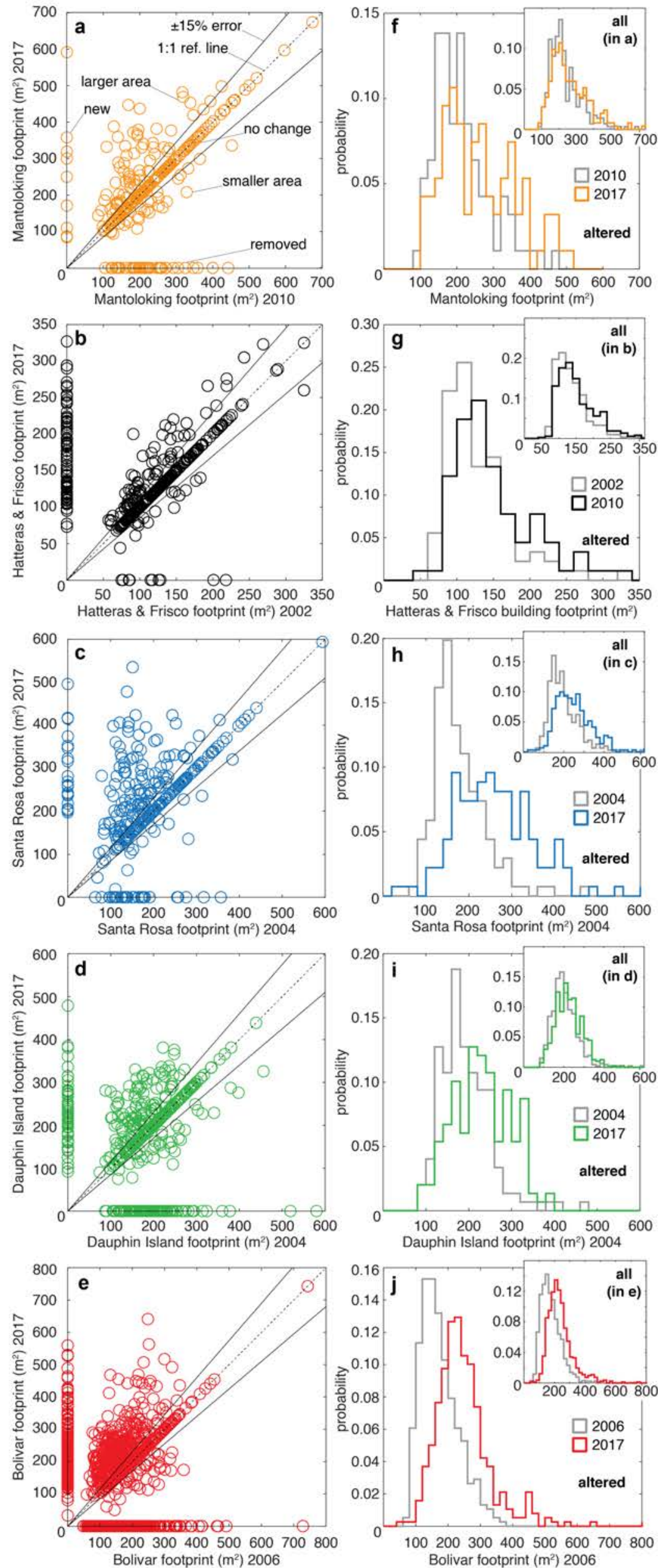

Figure 2 | Evidence of "building back bigger" in hurricane strike zones. a-e, Comparisons of building footprint size in pre-storm versus 2017 images, showing categorical changes in residential development.

Footprints for which the 2017 area is $\pm 15 \%$ (solid lines) of the prestorm area are considered unchanged (assumes difference is indistinguishable from potential error).

Dotted line marks reference line of 1:1 correspondence. $\mathbf{f}-\mathbf{j}$, Pre-storm and 2017 distributions of building footprints that changed in area; insets show pre-storm and 2017 distributions of all footprints. Note scales of axes differ by location. (Descriptive statistics and comparative tests for the data in this figure are available in Supplementary Tables 1 and 2.) 
199 Building footprints - We use publicly available imagery of requisite resolution and an

200 appropriate capture date, spanning a full timeframe from prior to the last major hurricane strike at each location up to the most recent available imagery (2017). Pre-storm and 2017 imagery for Mantoloking, Santa Rosa Island, Dauphin Island, and the Bolivar peninsula is sourced from Google Earth. Pre-storm imagery (2002) for Hatteras Village and Frisco (combined as "Hatteras") comes from the NC OneMap GeoSpatial Portal (http://data.nconemap.gov/geoportal/catalog/raster/download.page). FEMA Flood Risk Zone designations are available through the agency's Map Service Center (https://msc.fema.gov/portal/).

Building footprints were digitised manually and their areas calculated using GIS software. We digitised the roofed footprint of every residential building in the first three rows back from the "ocean-side" shorefront. At Mantoloking, north/south town boundaries set the sampling space. At Santa Rosa Island, we sampled the reach of coastline between the causeways at Pensacola Beach and Navarre Beach (west/east, respectively). At Hatteras/Frisco, Dauphin Island, and the Bolivar Peninsula (immediately northeast of Galveston), we sampled the full alongshore extents. These data (pre-storm and 2017 combined, $\sim 4800$ footprints) therefore represent a large sample or all of the single-family residential buildings at each location. Footprints were matched between images using a spatial join, then reviewed manually. Given inherent variability in pre-storm image quality (resolution or image tilt), we use a compensatory envelope of $\pm 15 \%$, which assumes that a building's 2017 footprint must change more than $\pm 15 \%$ to be distinguishable from potential error. This envelope is nearly four to five times greater than the $\sim 3-4 \%$ error variance attributable to our manual digitisation, and is therefore a conservative measure.

Summary magnitudes of change in footprint area do not correlate with elapsed time between images, nor do they indicate a geographic control (i.e., Atlantic versus Gulf Coast). Although we did not control for building characteristics (or demographics), we applied the same method to five distinct locations (each with $\sim 10-30 \mathrm{~km}$ of shoreline extent) and found the same pattern everywhere, suggesting that contextual biases in any one sample are not strong enough to skew the aggregate findings.

In the Supplementary Methods, we further discuss our locations, and compare a subset of our measured footprints to total living area reported in tax records (Supplementary Fig. 1; Supplementary Table 3).

Statistical analysis - To quantitatively distinguish between pre-storm and 2017 distributions of building size (Fig. $2 \mathrm{f}-\mathrm{j}$ and insets), we used a two-sample Kolmogorov-Smirnov (K-S) test with the null hypothesis that the two distributions could have come from the same continuous distribution. (A K-S test is applicable to non-parametric data.) We tested to the $\alpha=5 \%$ significance level (two-tailed); the asymptotic value $p$ is the probability of observing an equal or greater test statistic. Because some of the distributions are only weakly non-parametric, we also applied a paired $t$-test (for normal distributions), and find the same results. Sample sizes $(n)$ and values for significant and non-significant K-S and paired- $t$ tests are shown in Supplementary Table 2.

Data availability - Study data are available via Figshare (Lazarus, E. D., Limber, P. W. \& Goldstein, E. B. Data for "Building back bigger in hurricane strike zones", Figshare doi:10.6084/m9.figshare.7108763 (2018) [Ref. 21]). Coordinates for the start- and endpoints of the sampled areas are shown in Supplementary Table 4. 


\section{SUPPLEMENTARY INFORMATION}

\section{Building back bigger in hurricane strike zones}

Eli D Lazarus ${ }^{1}$, Patrick W Limber ${ }^{2,3}$, Evan B Goldstein ${ }^{4}$, Rosie Dodd ${ }^{5} \&$ Scott B Armstrong $^{1}$

${ }^{1}$ Environmental Dynamics Lab, School of Geography \& Environmental Science, University of Southampton, Southampton, UK

${ }^{2}$ Department of Marine Science, Coastal Carolina University, Conway, South Carolina, USA

${ }^{3}$ Pacific Coastal and Marine Science Center, United States Geological Survey, Santa Cruz, California, USA

${ }^{4}$ Department of Geological Sciences, University of North Carolina, Chapel Hill, North Carolina, USA

${ }^{5}$ School of Earth \& Ocean Sciences, Cardiff University, Cardiff, UK

*Correspondence to: E.D.Lazarus@soton.ac.uk 


\section{SUPPLEMENTARY METHODS}

Locations - We examined five locations on the US Atlantic and Gulf Coasts that have been struck by one or more hurricanes since 2003. Our selection of locations was determined in part by date and image suitability: satellite imagery collected prior to 2002 tended to lack resolution crisp enough for reliable digitisation. Collectively, these five locations have weathered six different hurricane systems between 2003 and 2012, and sustained damage from multiple types of impacts (e.g., wind, storm surge, waves). Each location occupies a developed coastal barrier in a different state, and, although FEMA flood-risk maps are known to vary in their quality and accuracy (see Supplementary Ref. 1), each location is demarcated in FEMA flood-risk maps a Special Flood Hazard Area - either Zone A (hundred-year flood zones) or Zone V (hundred-year coastal flood zones likely to experience "velocity" from storm surge or wave action). These traits thus lend the locations similar physical environmental settings and federal designations, but potentially different state and local land-use planning contexts. Furthermore, by spanning the longest period possible (5 years or longer) since the last major hurricane event at a given location, our analysis allows for both rapid and slow paces of residential recovery. (That is, aerial images from the 2017 hurricane season, for example, might show damage but not reconstruction.)

Each location is characterised primarily by single-family residential buildings: where possible, we confirmed this building-type classification with tax records (Supplementary Fig. 1). To sample conservatively, we did not digitise buildings with visible adjacent parking lots, assuming they served either multi-unit condominiums or commercial buildings. Although a given building may have changed from a single-family residence to a commercial space (or vice versa), we expect the impact of any such buildings on the statistical analysis is negligible, given the large number of individual buildings we sampled.

This analysis is preliminary: it is limited to five US sites, and is not an exhaustive list of all sites on developed coastal barriers that have sustained hurricane damage (even in the US). Nevertheless, these preliminary results are instructive and motivate further work. Depending on imagery and data availability, the same comparative-footprint approach could be extended to other locations prone to cyclones (or other hazard types), and even applied in the absence of any recent cyclone (or other hazard) activity. Integrating a deliberately simplified analysis like ours with detailed collation of tax records, permits, construction types, and code variances (see Refs. $8,11 \& 12$ in the main text) would reflect the influence of political, legal, planning and other policy mechanisms in the coastal zone. But even in the absence of such detailed homeowner data (particularly outside the US), our methodology still quantifies broad development trends in ways that may help the wider sustainability-science research community to identify, understand, address the economic and policy forces that shape decision-making and risk evolution in hurricane alleys (and other hazard zones).

Comparison of total living area to measured footprints - Property taxes (and national Census statistics) report the total living area of a house, not its plan-view footprint. The roofed footprint that we digitise might approximately match the total living area for a single-storey house, but will almost certainly under-predict the total living area of a multi-storey building. For a building with deep covered porches, which do not count toward living area, our measurement of the roofed footprint will tend to over-predict the size of the actual (taxed) total living area.

To estimate how our footprint data scale relative to total living area, we compared the 2017 footprints of front-row properties from Hatteras/Frisco and Santa Rosa Island to total living area reported in property tax records as of 2016 (Supplementary Fig. 1). We use these two locations because their tax records are publicly available online: Hatteras/Frisco via Dare County (https://tax.darecountync.gov/parcelcard.php?parcel=); Santa Rosa Island 
via the Florida Geographic Data Library

(https://www.fgdl.org/metadataexplorer/explorer.jsp).

We find that total living area is, on average, $~ 94 \%$ larger than footprint area at Hatteras/Frisco, and $\sim 39 \%$ higher at Santa Rosa Island (Supplementary Fig. 1, insets). Applying these scaling factors, respectively, to our mean footprints allows us to compare our measurements to national statistics (via the US Census Bureau) for mean total floor area in new single-family houses (Supplementary Table 3). By direct comparison, according to the sizes reported in tax records, the mean size of (front-row) single-family residential buildings in our 2017 sample from Hatteras/Frisco are 28\% larger than the 2016 national average for new single-family houses; our sample from Santa Rosa Island are 47\% larger than the 2016 national average.

Note that our measured samples include all existing buildings, not just those built most recently. Hypothetically, a location where development exactly matches the national trend in new houses each year will, over time, end up with an overall mean house size that is smaller than the mean size for the most recent year. (For example: the mean of the national mean new house size between 2002-2016 is $231 \mathrm{~m}^{2}$, or $6 \%$ smaller than the national mean for new houses $\left(245 \mathrm{~m}^{2}\right)$ in 2016.)

\section{Supplementary References}

1. Wing, O. E., Bates, P. D., Smith, A. M., Sampson, C. C., Johnson, K. A., Fargione, J., \& Morefield, P. Estimates of present and future flood risk in the conterminous United States. Environ. Res. Lett. 13, 034023 (2018).

\section{SUPPLEMENTARY FIGURES}
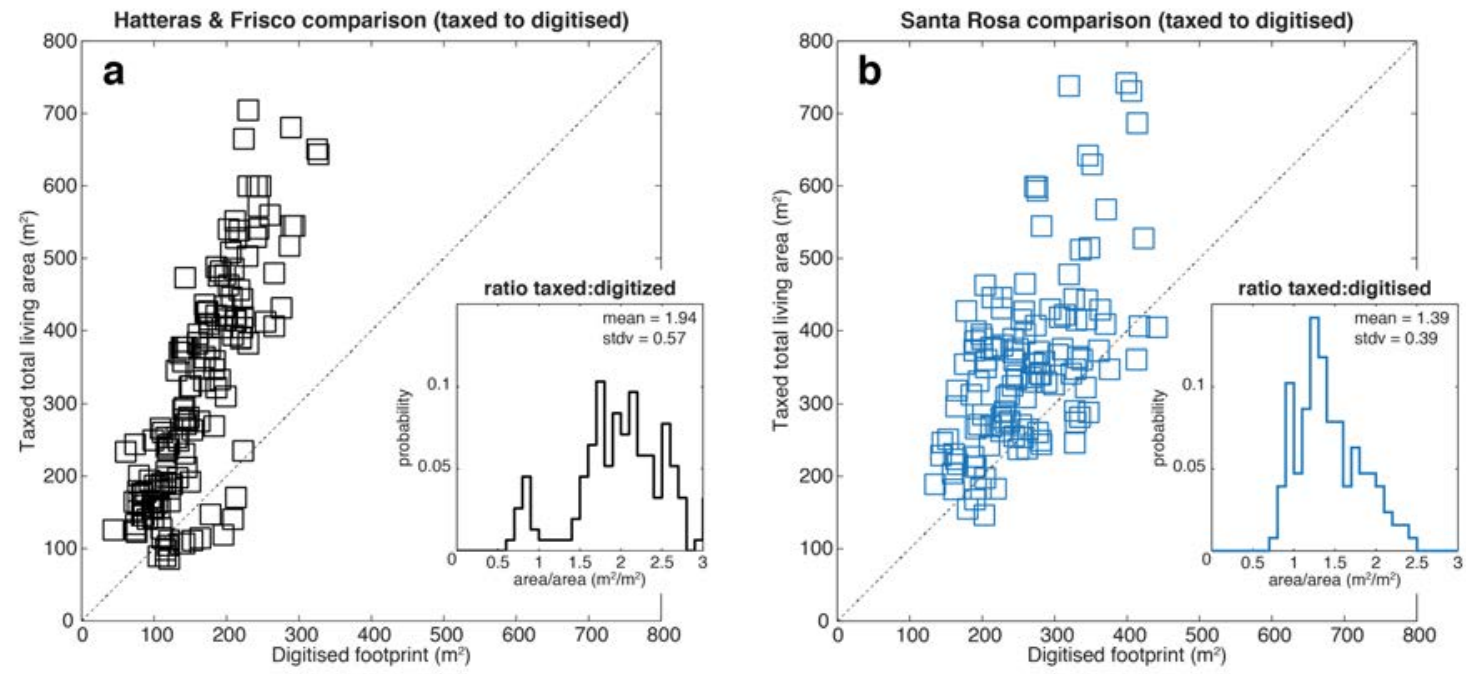

Supplementary Figure 1 | Comparison of taxed total living area to footprint area. a, Scaling relationship for Hatteras/Frisco, with ratio distribution (taxed to digitised) shown in inset. $\mathbf{b}$, Scaling relationship for Santa Rosa Island. These data reflect shorefront (first row), single-family houses from both locations, and compare 2016 tax information to footprints digitised from 2017 imagery (data presented in the main article). Dotted lines show the 1:1 reference line. 


\section{SUPPLEMENTARY TABLES}

Supplementary Table 1 | Descriptive statistics for footprint data (sample counts, totals, means) in this study. (For comparative statistical tests, see Supplementary Table 2.)

\begin{tabular}{|c|c|c|c|c|c|c|}
\hline & Mantoloking & Hatteras & Santa Rosa & Dauphin & Bolivar & \\
\hline pre-storm year $^{a}$ & 2010 & 2002 & 2004 & 2004 & 2006 & \\
\hline years between images & 7 & 15 & 13 & 13 & 11 & \\
\hline storm year(s) & 2012 & 2003 & 2004,2005 & 2004,2005 & 2008 & \\
\hline years since last hurricane strike & 5 & 14 & 12 & 12 & 7 & \\
\hline 2017 image (all) & 252 & 375 & 291 & 401 & 823 & 2142 \\
\hline total altered & 94 & 90 & 136 & 149 & 379 & 848 \\
\hline altered+ (area increased) & 67 & 74 & 121 & 112 & 339 & 713 \\
\hline altered- (area decreased) & 27 & 16 & 15 & 37 & 40 & 135 \\
\hline new build & 9 & 81 & 20 & 60 & 196 & 366 \\
\hline new as $\% 2017$ total & $4 \%$ & $22 \%$ & $7 \%$ & $15 \%$ & $24 \%$ & \\
\hline removed as $\%$ pre-storm total & $15 \%$ & $3 \%$ & $11 \%$ & $26 \%$ & $52 \%$ & \\
\hline \multicolumn{7}{|l|}{ Total footprint areas $\left(\mathrm{m}^{2}\right)$} \\
\hline pre-storm (all) & 67343 & 38350 & 57493 & 90375 & 217767 & \\
\hline 2017 (all) & 64979 & 53713 & 70088 & 87030 & 186596 & \\
\hline altered (pre-storm area) & 19253 & 10787 & 22951 & 27300 & 61988 & \\
\hline altered (2017 area) & 23919 & 12794 & 34222 & 33099 & 89590 & \\
\hline altered+ (pre-storm area) & 12961 & 8552 & 19927 & 18689 & 52770 & \\
\hline altered+ $+(2017$ area $)$ & 19220 & 11084 & 32046 & 26989 & 83450 & \\
\hline new & 2271 & 14136 & 5902 & 13979 & 44184 & \\
\hline removed & 9539 & 1228 & 5537 & 23192 & 103684 & \\
\hline pre-storm & $235(118)$ & $126(46)$ & $188(73)$ & $196(65)$ & $168(69)$ & \\
\hline 2017 & $258(134)$ & $143(53)$ & $241(90)$ & $217(64)$ & $227(84)$ & \\
\hline difference & 23 & 17 & 53 & 21 & 59 & \\
\hline difference as $\%$ pre & $10 \%$ & $14 \%$ & $28 \%$ & $11 \%$ & $35 \%$ & \\
\hline \multicolumn{7}{|l|}{ Footprint $\left(\mathrm{m}^{2}\right)$ means: altered $(1 \mathrm{stdv})$} \\
\hline pre-storm & $205(77)$ & $120(47)$ & $169(62)$ & $183(60)$ & $164(58)$ & \\
\hline 2017 & $254(101)$ & $142(56)$ & $252(95)$ & $222(68)$ & $236(87)$ & \\
\hline difference & 50 & 22 & 83 & 39 & 72 & \\
\hline difference as $\%$ pre & $24 \%$ & $19 \%$ & $49 \%$ & $21 \%$ & $44 \%$ & \\
\hline altered+ pre (mean) & $193(74)$ & $116(44)$ & $165(58)$ & $167(44)$ & $185(66)$ & \\
\hline altered +2017 (mean) & $287(96)$ & $150(55)$ & $265(89)$ & $241(60)$ & $291(105)$ & \\
\hline diff. in altered+ (2017 to pre) & 93 & 34 & 100 & 74 & 105 & \\
\hline diff. in altered+ as $\%$ pre altered + & $48 \%$ & $30 \%$ & $61 \%$ & $44 \%$ & $57 \%$ & \\
\hline altered- pre (mean) & $233(80)$ & $140(59)$ & $202(84)$ & $233(76)$ & $258(71)$ & \\
\hline altered- 2017 (mean) & $174(63)$ & $107(49)$ & $145(77)$ & $165(57)$ & $176(54)$ & \\
\hline diff. in altered- (2017 to pre) & -59 & -33 & -57 & -68 & -82 & \\
\hline diff. in altered- as $\%$ pre altered- & $-25 \%$ & $-23 \%$ & $-28 \%$ & $-29 \%$ & $-32 \%$ & \\
\hline \multicolumn{7}{|l|}{ Footprint $\left(m^{2}\right)$ means: new (1 stdv) } \\
\hline pre-storm ('pre-storm means all', above) & $235(118)$ & $126(46)$ & $188(73)$ & $196(65)$ & $168(69)$ & \\
\hline 2017 & $252(164)$ & $175(56)$ & $295(83)$ & $233(71)$ & $225(90)$ & \\
\hline difference & 18 & 48 & 107 & 37 & 57 & \\
\hline difference as $\%$ pre & $14 \%$ & $26 \%$ & $55 \%$ & $19 \%$ & $34 \%$ & \\
\hline
\end{tabular}

a Imagery from 2004 (for Santa Rosa Island and Dauphin Island) was captured in March; Hurricane Ivan passed in September.

b Imagery from 2017 for Bolivar was captured in February, several months prior to the 2017 hurricane season. 
Supplementary Table 2 | Statistical tests (Kolmogorov-Smirnov; two-sample $t$ test) comparing pre-storm and 2017 footprint distributions (shown in Fig. 2) and comparing pre-storm versus "survivor" footprints. All tests are two-tailed at $\alpha=5 \%$ significance level; all areas in $\mathrm{m}^{2}$. (Table footnotes on next page.)

\begin{tabular}{|c|c|c|c|c|c|}
\hline & Mantoloking & Hatteras & Santa Rosa & Dauphin & Bolivar \\
\hline \multicolumn{6}{|c|}{ Comparison of all building footprints (pre-storm to 2017) } \\
\hline \multicolumn{6}{|c|}{ Distribution statistics: all footprints $\left(\mathrm{m}^{2}\right)$} \\
\hline number in sample: pre-storm image & 287 & 304 & 306 & 462 & 1295 \\
\hline number in sample: 2017 image & 252 & 375 & 291 & 401 & 823 \\
\hline pre-storm mean footprint area (1 stdv) & $235(118)$ & $126(46)$ & $188(73)$ & $196(65)$ & $168(69)$ \\
\hline 2017 mean footprint area (1 stdv) & $258(134)$ & $143(53)$ & $241(90)$ & $217(64)$ & $227(84)$ \\
\hline difference & 23 & 17 & 53 & 21 & 59 \\
\hline difference as $\%$ pre-storm & $10 \%$ & $14 \%$ & $28 \%$ & $11 \%$ & $35 \%$ \\
\hline \multicolumn{6}{|c|}{ KS test: all footprints (sample size $n$; pre-storm \& 2017) - null hypothesis: samples come from same distribution } \\
\hline hypothesis $(1=\text { reject null) })^{\text {a }}$ & $1(287,252)$ & $1(304,375)$ & $1(306,291)$ & $1(462,401)$ & $1(1295,823)$ \\
\hline$p$-value ${ }^{\mathrm{b}}$ & $4.31 \mathrm{E}-02$ & $5.05 \mathrm{E}-04$ & $1.96 \mathrm{E}-13$ & $1.26 \mathrm{E}-08$ & $8.68 \mathrm{E}-55$ \\
\hline test statistic & 0.1183 & 0.1555 & 0.3136 & 0.2079 & 0.3507 \\
\hline \multicolumn{6}{|c|}{ paired $t$ test: all footprints (sample size $n$; pre-storm \& 2017) - null hypothesis: samples come from same distribution } \\
\hline hypothesis $(1=\text { reject null })^{\mathrm{C}}$ & $1(287,252)$ & $1(304,375)$ & $1(306,291)$ & $1(462,401)$ & $1(1295,823)$ \\
\hline$p$-value & 0.0329 & $1.05 \mathrm{E}-05$ & 1.37E-14 & $1.49 \mathrm{E}-6$ & $3.72 \mathrm{E}-64$ \\
\hline \multicolumn{6}{|c|}{ Comparison of altered building footprints (pre-storm to 2017) } \\
\hline \multicolumn{6}{|l|}{ Distribution statistics: altered footprints $\left(\mathrm{m}^{2}\right)$} \\
\hline number in sample: altered & 94 & 90 & 136 & 149 & 379 \\
\hline pre-storm mean footprint area (1 stdv) & $205(77)$ & $120(47)$ & $169(62)$ & $183(60)$ & $164(58)$ \\
\hline 2017 mean altered footprint area (1 stdv) & $254(101)$ & $142(56)$ & $252(95)$ & $222(68)$ & $236(87)$ \\
\hline difference & 50 & 22 & 83 & 39 & 72 \\
\hline difference as \% pre-storm & $24 \%$ & $19 \%$ & $49 \%$ & $21 \%$ & $44 \%$ \\
\hline \multicolumn{6}{|c|}{ KS test: altered footprints (sample size $n$; pre-storm \& 2017) - null hypothesis: samples come from same distribution } \\
\hline hypothesis $(1$ = reject null) & $1(94,94)$ & $1(90,90)$ & $1(136,136)$ & $1(149,149)$ & $1(379,379)$ \\
\hline$p$-value & $2.00 \mathrm{E}-03$ & $1.40 \mathrm{E}-03$ & 1.63E-13 & $4.60 \mathrm{E}-07$ & $9.12 \mathrm{E}-34$ \\
\hline test statistic & 0.2660 & 0.2778 & 0.4632 & 0.3154 & 0.4459 \\
\hline \multicolumn{6}{|c|}{ paired $t$ test: altered footprints (sample size $n$; pre-storm \& 2017) - null hypothesis: samples come from same distribution } \\
\hline hypothesis $(1=$ reject null) & $1(94,94)$ & $1(90,90)$ & $1(136,136)$ & $1(149,149)$ & $1(379,379)$ \\
\hline$p$-value & $2.13 \mathrm{E}-04$ & 0.0044 & $1.34 \mathrm{E}-15$ & $2.99 \mathrm{E}-07$ & $8.82 \mathrm{E}-38$ \\
\hline \multicolumn{6}{|c|}{ Comparison of new building footprints (pre-storm to 2017) } \\
\hline \multicolumn{6}{|c|}{ Distribution statistics: new footprints $\left(\mathrm{m}^{2}\right)$} \\
\hline number in sample: pre-storm image & 287 & 304 & 306 & 462 & 1295 \\
\hline number in sample: new since pre-storm & 9 & 81 & 20 & 60 & 196 \\
\hline pre-storm mean footprint area (1 stdv) & $235(118)$ & $126(46)$ & $188(73)$ & $196(65)$ & $168(69)$ \\
\hline 2017 mean new footprint area (1 stdv) & $252(164)$ & $175(56)$ & $295(83)$ & $233(71)$ & $225(90)$ \\
\hline difference & 18 & 48 & 107 & 37 & 57 \\
\hline difference as $\%$ pre-storm & $14 \%$ & $26 \%$ & $55 \%$ & $19 \%$ & $34 \%$ \\
\hline \multicolumn{6}{|c|}{ KS test: new footprints (sample sizes $n$; pre-storm all \& new) - null hypothesis: samples come from same distribution } \\
\hline hypothesis $(1$ = reject null) & $0(287,9)$ & $1(304,81)$ & $1(306,20)$ & $1(462,60)$ & $1(1295,196)$ \\
\hline$p$-value & 0.3405 & 2.15E-09 & 8.59E-08 & 5.10E-07 & 7.53E-14 \\
\hline test statistic & 0.3020 & 0.3952 & 0.6503 & 0.3712 & 0.2984 \\
\hline \multicolumn{6}{|c|}{ paired $t$ test: new footprints (sample sizes $n$; pre-storm all $\&$ new) - null hypothesis: samples come from same distribution } \\
\hline hypothesis $(1=$ reject null) & $0(287,9)$ & $1(304,81)$ & $1(306,20)$ & $1(462,60)$ & $1(1295,196)$ \\
\hline$p$-value & 0.3405 & 2.15E-09 & 8.59E-08 & $5.10 \mathrm{E}-07$ & $7.73 \mathrm{E}-14$ \\
\hline \multicolumn{6}{|c|}{ Comparison of "surviving" building footprints ${ }^{d}$ (pre-storm to 2017) } \\
\hline \multicolumn{6}{|c|}{ Distribution statistics: surviving building footprints $\left(\mathrm{m}^{2}\right)$} \\
\hline number in sample: pre-storm image (all) & 287 & 304 & 306 & 462 & 1295 \\
\hline number in sample: surviving buildings & 243 & 293 & 270 & 341 & 627 \\
\hline surviving buildings as $\%$ of pre-storm total & $85 \%$ & $96 \%$ & $88 \%$ & $74 \%$ & $48 \%$ \\
\hline pre-storm mean footprint area all (1 stdv) & $235(118)$ & $126(46)$ & $188(73)$ & $196(65)$ & $168(69)$ \\
\hline "surviving" mean footprint area (1 stdv) & $239(129)$ & $128(46)$ & $195(77)$ & $197(61)$ & $183(67)$ \\
\hline difference as $\%$ of "pre-storm all" mean & $2 \%$ & $2 \%$ & $4 \%$ & $1 \%$ & $9 \%$ \\
\hline \multicolumn{6}{|c|}{ KS test: surviving buildings (sample size $n$; pre-storm all \& surviving) - null hypothesis: samples come from same distribution } \\
\hline hypothesis $(1$ = reject null) & $0(287,243)$ & $0(304,293)$ & $0(306,270)$ & $0(462,341)$ & $1(1295,627)$ \\
\hline$p$-value & 0.9998 & 0.9992 & 0.4159 & 0.60889 & 1.72E-05 \\
\hline test statistic & 0.0296 & 0.02996 & 0.0730 & 0.0538 & 0.1168 \\
\hline \multicolumn{6}{|c|}{ paired $t$ test: surviving buildings (sample size $n$; pre-storm all \& surviving) - null hypothesis: samples come from same distribution } \\
\hline hypothesis $(1=$ reject null) & $0(287,243)$ & $0(304,293)$ & $0(306,270)$ & $0(462,341)$ & $1(1295,627)$ \\
\hline$p$-value & 0.6956 & 0.9992 & 0.2262 & 0.7223 & $7.82 \mathrm{E}-06$ \\
\hline
\end{tabular}




\section{[Supplementary Table 2 footnotes ]}

a In a two-sample Kolmogorov-Smirnov test, the null hypothesis is that data in the two samples come from the same continuous distribution. The alternative hypothesis is that the two samples are from different continuous distributions. The result of 1 indicates that the test rejects the null hypothesis at the $\boldsymbol{\alpha}=5 \%$ significance level.

${ }^{\mathrm{b}} p$ is the probability of observing a test statistic as extreme as, or more extreme than, the observed value under the null hypothesis.

c In a two-sample $t$ test, the null hypothesis is that data in the two samples come from independent random samples from normal distributions with equal means and equal but unknown variances. The alternative hypothesis is that the data comes from populations with unequal means. The result of 1 indicates that the test rejects the null hypothesis at the $\boldsymbol{\alpha}=5 \%$ significance level.

d Hypothetically, total footprint area could change with preferential destruction or removal of buildings of a given size, without otherwise altering footprints of existing buildings. We test for this effect by comparing the mean pre-storm footprint of "surviving" buildings those present in both images - with the mean pre-storm footprint overall. The only significant difference we find is at Bolivar, where smaller buildings were disproportionately affected. However, the preferential loss of smaller footprints only accounts for a $9 \%$ increase in mean footprint size.

Supplementary Table 3 | Comparisons of data from this study to national trends in house size.

\begin{tabular}{|c|c|c|c|c|c|}
\hline & Mantoloking & Hatteras & Santa Rosa & Dauphin & Bolivar \\
\hline \multicolumn{6}{|c|}{ National mean total floor area $\left(\mathrm{m}^{2}\right)$ in new single-family houses completed ${ }^{a}$} \\
\hline image pairs (pre-storm year, 2017) & 2010,2017 & 2002,2017 & 2004,2017 & 2004,2017 & 2006,2017 \\
\hline mean area in year of pre-storm image & 222 & 216 & 218 & 218 & 229 \\
\hline mean area in "final" year $(2016)^{b}$ & 245 & 245 & 245 & 245 & 245 \\
\hline difference (post to pre) & 23 & 29 & 27 & 27 & 16 \\
\hline change as $\%$ pre-storm mean & $10 \%$ & $14 \%$ & $12 \%$ & $12 \%$ & $7 \%$ \\
\hline max. area in pre/post span (year) & $250(2015)$ & $250(2015)$ & $250(2015)$ & $250(2015)$ & $250(2015)$ \\
\hline max. difference ${ }^{c}$ & 28 & 34 & 32 & 32 & 21 \\
\hline max. change as $\%$ pre-storm mean & $12 \%$ & $16 \%$ & $14 \%$ & $14 \%$ & $9 \%$ \\
\hline \multicolumn{6}{|l|}{ Footprints (this study) } \\
\hline change as $\%$ pre-storm mean (all) & $10 \%$ & $14 \%$ & $28 \%$ & $11 \%$ & $35 \%$ \\
\hline change as $\%$ pre-storm mean (altered) & $24 \%$ & $19 \%$ & $49 \%$ & $21 \%$ & $44 \%$ \\
\hline change as \% pre-storm mean (new) & $14 \%$ & $26 \%$ & $55 \%$ & $19 \%$ & $34 \%$ \\
\hline \multicolumn{6}{|c|}{ Footprints - total living area (taxed) vs digitised footprint } \\
\hline sample size ( $(n$, from front row only) & - & 156 & 128 & - & - \\
\hline mean taxed total living area $\left(\mathrm{m}^{2}, 1 \mathrm{stdv}\right)$ & - & $313(155)$ & $360(133)$ & - & - \\
\hline mean ratio (taxed area to post footprint) & - & 1.94 & 1.39 & - & - \\
\hline standard deviation of mean ratio & - & 0.57 & 0.39 & - & - \\
\hline$\%$ diff. relative to 2016 national mean & - & $28 \%$ & $47 \%$ & - & - \\
\hline \multicolumn{6}{|c|}{ Footprint means: scaled estimations (see Supplementary Fig. 1 \& Supplementary Methods) ${ }^{d}$} \\
\hline mean footprints (pre, all) $\times 1.4$ & 329 & 176 & 263 & 274 & 235 \\
\hline as \% national mean (pre) & $48 \%$ & $-18 \%$ & $21 \%$ & $26 \%$ & $3 \%$ \\
\hline mean footprints $(2017$, all $) \times 1.4$ & 361 & 200 & 337 & 304 & 318 \\
\hline as \% national mean (2017) & $47 \%$ & $-18 \%$ & $38 \%$ & $24 \%$ & $30 \%$ \\
\hline mean footprints (pre, altered) $\times 1.4$ & 287 & 168 & 237 & 256 & 230 \\
\hline as \% national mean (pre) & $29 \%$ & $-22 \%$ & $\mathbf{9 \%}$ & $18 \%$ & $\approx$ \\
\hline mean footprints (2017, altered) $\times 1.4$ & 356 & 199 & 353 & 311 & 330 \\
\hline as $\%$ national mean $(2017)$ & $45 \%$ & $-19 \%$ & $44 \%$ & $27 \%$ & $35 \%$ \\
\hline mean footprints (new) $\times 1.4$ & 353 & 245 & 413 & 326 & 315 \\
\hline as \% national mean (2017) & $44 \%$ & $0 \%$ & $69 \%$ & $33 \%$ & $29 \%$ \\
\hline mean footprints (pre, all) $\times 1.9$ & 447 & 239 & 357 & 372 & 319 \\
\hline as \% national mean (pre) & $101 \%$ & $11 \%$ & $64 \%$ & $71 \%$ & $39 \%$ \\
\hline mean footprints $(2017$, all $) \times 1.9$ & 490 & 272 & 458 & 412 & 431 \\
\hline as \% national mean (2017) & $100 \%$ & $11 \%$ & $87 \%$ & $68 \%$ & $76 \%$ \\
\hline mean footprints (pre, altered) $\times 1.9$ & 390 & 228 & 321 & 348 & 312 \\
\hline as \% national mean (pre) & $75 \%$ & $6 \%$ & $47 \%$ & $59 \%$ & $36 \%$ \\
\hline mean footprints (2017, altered) x 1.9 & 483 & 270 & 479 & 422 & 448 \\
\hline as $\%$ national mean $(2017)$ & $97 \%$ & $10 \%$ & $95 \%$ & $72 \%$ & $83 \%$ \\
\hline mean footprints (new) $\times 1.9$ & 479 & 333 & 561 & 443 & 428 \\
\hline as \% national mean (2017) & $95 \%$ & $36 \%$ & $129 \%$ & $81 \%$ & $74 \%$ \\
\hline
\end{tabular}

${ }^{a}$ US Census Bureau, 2016 Characteristics of New Housing, available at: https://www.census.gov/construction/chars/pdf/c25ann2016.pdf b Digitised images were captured in 2017, but most recent year available for national housing characteristics is 2016.

${ }^{c}$ Note that in 2015, the mean total floor area was $250 \mathrm{~m}^{2}$. Therefore, between 2002-2016 (the maximum span of our analysis, measured at Hatteras/Frisco), the maximum change in mean floor area was $16 \%$.

d Bold columns indicate direct scaling comparison (e.g., estimated values for Santa Rosa based on scaling factor specific to Santa Rosa). 
Supplementary Table 4 | End-point coordinates (in decimal degrees) for locations sampled (see also Ref. 21 in main article for data repository).

\begin{tabular}{|l|l|l|}
\hline Location & Start (north or west) & End (south or east) \\
\hline Mantoloking, NJ & $40.058447^{\circ},-74.045709^{\circ}$ & $40.026381^{\circ},-74.053804^{\circ}$ \\
\hline Hatteras/Frisco, NC & $35.205950^{\circ},-75.702756^{\circ}$ & $35.229029^{\circ},-75.625388^{\circ}$ \\
\hline Santa Rosa, FL & $30.333611^{\circ},-87.130948^{\circ}$ & $30.378038^{\circ},-86.880504^{\circ}$ \\
\hline Dauphin, AL [segment 1] & $30.248554^{\circ},-88.191982^{\circ}$ & $30.251080^{\circ},-88.138527^{\circ}$ \\
\hline Dauphin, AL [segment 2] & $30.244266^{\circ},-88.105405^{\circ}$ & $30.247469^{\circ},-88.076565^{\circ}$ \\
\hline Bolivar, TX & $29.396736^{\circ},-94.718203^{\circ}$ & $29.521562^{\circ},-94.462669^{\circ}$ \\
\hline
\end{tabular}

